\title{
A STEM Model to Engage Students in Environmental Sustainability Program Through Problem-solving Approach- Case Study in Qatar
}

Rania Aledamat, Azza Abouhashem, Ruba Ali, Shahad Alkhair, Jolly Bhadra, Dr. Noora Al-Thani, Qatar University Young Scientists center

\section{ABSTRACT}

Environmental development was highlighted as one of the vision's four pillars following the launch of Qatar's national Vision 2030.

The importance of developing people's awareness of their duty in maintaining the country's environment for future generations.

- Environmental education can be combined with various approaches, such as STEM and problem-solving skills, making it an excellent way to engage students in a sustainable program.

A distinctive E-STEM program titled "ProblemSolving" (PS) was developed in Qatar amid regular educational reforms to improve primary school pupils' problem-solving abilities.

During this study, 346 kids (202 females and 144 males) from 14 different public and private primary schools were given STEM workshops on environmental issues, encouraging them to develop solutions to the problem.

The study used a mixed-method approach to measure program efficacy,

- $\mathrm{t}$-test statistical analysis

- pre-and post-questionnaires - SWOT analysis

\section{OBJECTIVES}

The sole goal of the research was to familiarize participants with problem-solving abilities and their application in everyday life through tackling environmental concerns. The following are the research questions that will be addressed during our investigation:

1. Were the participants able to develop problem-solving abilities in order to solve challenges in their everyday lives?

2. Was the integration of collaborative problemsolving abilities with an E-STEM program successful due to the program design and content?

3. Will students in Qatar gain a better awareness of environmental challenges as a result of the program?

4. The research elicited excellent primary students' attitudes and self-efficacy in conducting scientific experiments.

5. To entice Qatari youngsters to complete the program's objectives, a rigorous, supportive learning environment based on environmental issues was established.

6. By using collaborative problem-solving skills as a framework in an E-STEM program, the project studied the numerous possibilities for students to improve scientific skills.

\section{METHODOLOGY}

Table 1 shows the demographics of the participants as well as the ercentage of students. The overall number of participants during the two years program was 346.

\begin{tabular}{|c|c|c|c|c|}
\hline \multirow{2}{*}{ Workshops } & \multicolumn{4}{|c|}{ Number of Participants } \\
\cline { 2 - 5 } & M & $\%$ & F & $\%$ \\
\hline $\begin{array}{c}\text { W-1 } \\
\text { Environmentally } \\
\text { Friendly Challenge }\end{array}$ & 28 & 35 & 52 & 65 \\
\hline $\begin{array}{c}\text { W-2 } \\
\text { Waste Challenge }\end{array}$ & 43 & 37 & 73 & 63 \\
\hline $\begin{array}{c}\text { W-3 } \\
\text { Water Problems }\end{array}$ & 25 & 35.2 & 46 & 64.8 \\
\hline $\begin{array}{c}\text { W-4 } \\
\text { Rise of Earth } \\
\text { Temperature }\end{array}$ & 48 & 60.8 & 31 & 39.2 \\
\hline Total & 144 & 41.6 & 202 & 58.4 \\
\hline
\end{tabular}

\section{METHODOLOGY}

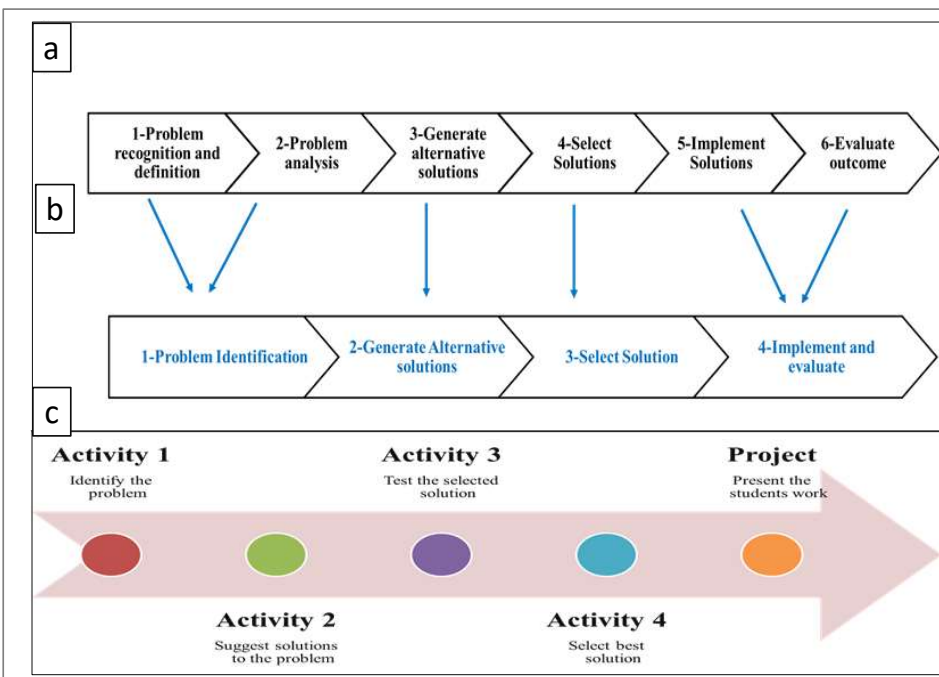

Figure 1: Schematic diagram of "Problem-solving" program methodology. a-Illustrates the Rational Problem-Solving Approach, proposed by John Dewey in 1910. b- the modified
layout is provided for all workshops, W-1,W-2, W-3, and W-4

\section{RESULTS and DISCUSSION}

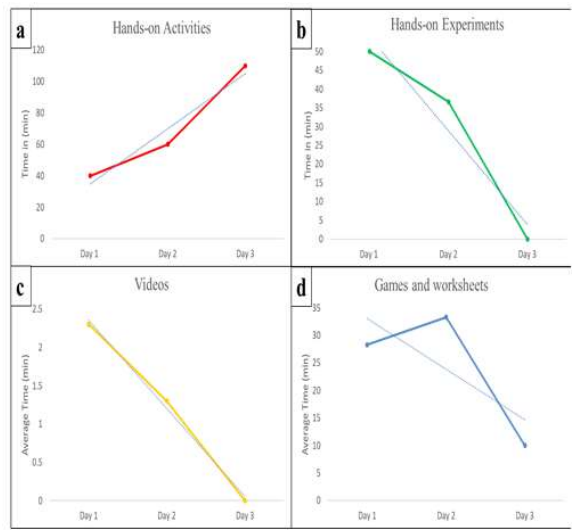

Figure 2: A diagram illustration of the duration of the various educationa tools applied during each workshop. (a) Hands-o

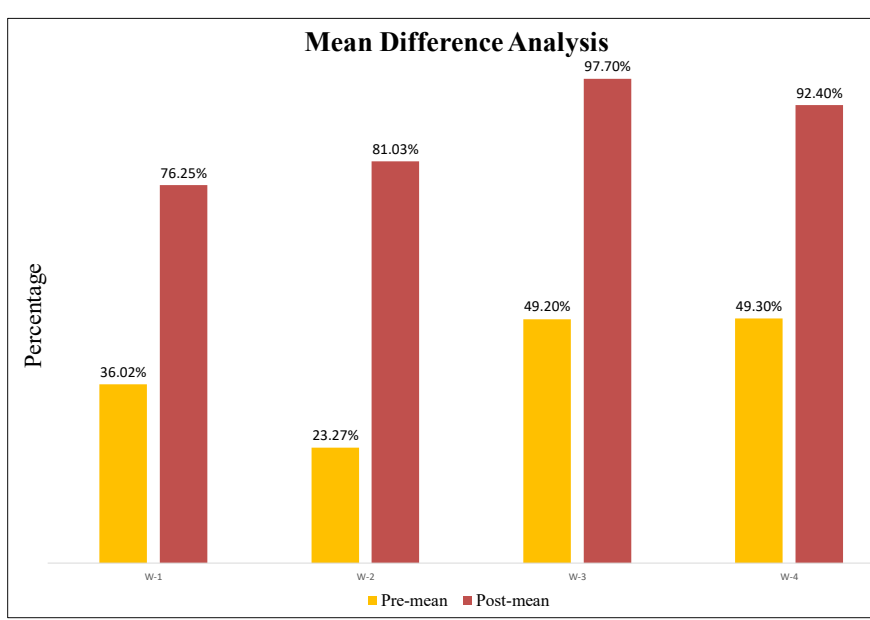

Figure 4: The comparison between the Pre-test and Post-test means the difference of students' population (n=346) over the program's two-year period. The Red and Green lines represent the pre-test mean and post-test mean percentage of the questionnaire analysis data collected from the two-year experiment. Again, the program proves to be effective in improving tudents'attitudes by a significant margin.

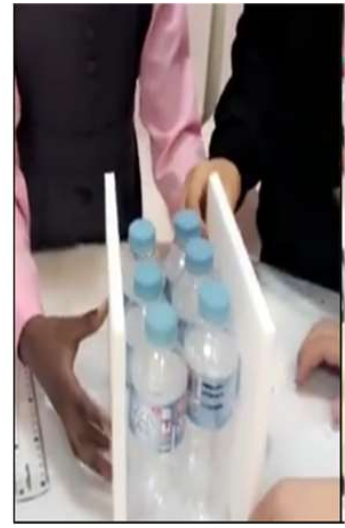

Figure 3:Different design prototypes of $W-1$ Figure 3:Different design prototypes of $W-1$
and $W-2$.$) recycled table from bottles and$ and $W$-2.)

\section{ACKNOWLEDGMENT}

We would like to Thank Partners UNESCO and Qatar National Commission and QUYSC for their continuous support.

\section{REFERENCES}

1- General Secretariat For Development Planning "Qatar Vision 2030". Doha Towers PO Box 1855 Doha, Qatar. www.planning.gov.qa

2- UNESCO (2018) Issues and trends in Education for Sustainable Development. Paris. pp. 26, 27. ISBN 978-92-3-100244-1.

3- Mulyadi, B. ENIS Model of Environmental Education for Elementary School Students in Japan. 2020, E3S Web of Conferences 202, 03019 https://doi.org/10.1051/e3sconf/202020203019 4- Chen et al. (2019)Research and Practice in Technology Enhanced Learning (2019) 14:24 https://doi.org/10.1186/s41039-019-0119-y

5- Levi, D. Group Dynamics of Teams, Edition 4 Chapter 11: problem-solving pp. 203-214 (2015) SAGE Publications, Inc. 